Ciência e Natura, v. 37 Part 2 2015, p. 415-426

\title{
Design and analysis of energy transfer system through Inductive Power Transfer (IPT) connected to a solar panel
}

\author{
Naeim Najafi ${ }^{1}$, Amirhossein Rajaei ${ }^{1}$, Mohammad Mardaned $^{1}$ \\ ${ }^{1}$ Shiraz University of Technology, Department of Electrical and Electronic Engineering
}

\begin{abstract}
In this article, Inductive Power Transfer (IPT) system fed by a suggested panel and its various stages of design and analysis are described. Typically, IPT with its separate control system, and solar panel with its separate Maximum power point tracking (MPPT) unit works together to achieve maximum efficiency. This use of two separate converters reduces the efficiency and reliability of the entire system. Therefore, a system is recommended so that while eliminating the MPPT unit and considering design considerations, we can make MPPT function occur in the IPT control circuit. Simulation of the conventional and the proposed system shows that with removal of MPPT, the system efficiency increases from $90 \%$ to $93 \%$.
\end{abstract}

Keywords: Inductive Power Transfer (IPT), wireless charging, solar energy, MPPT system. 


\section{Introduction}

$\mathrm{I}$ $\mathrm{n}$ the last decade, due to environmental considerations and the rising cost of fossil fuels and their limited resources, more attention has been paid to the technology of electric cars [1]. Therefore, researchers and car manufacturers are trying to work on ideas that make such vehicles cheaper, more efficient and more reliable. One of the related areas is that of electric vehicle charging systems and a new related technology, i.e. charging with IPT. This study introduces and analyzes a charger in which a solar panel is combined with IPT system and can charge the batteries of electric vehicles in an optimal way. The usual method of charging electric vehicles is connection to power with copper cable. Such charging systems starts from level 1 (more than $1 \mathrm{~kW}$ ) up to level 2 (more than $19.8 \mathrm{~kW}$ ) based on $\mathrm{SAE}^{1}$ standard system [2]. In this charging method an empty battery usually takes a night to get fully charged. This long charging time and the lack of available sockets everywhere are among problems of this method. To overcome these disadvantages, an IPT charging system is presented here. In this method, using time-varying magnetic field, power is transferred from an air gap to the car body. The advantages of this method are as follows:

- Charging convenience. IPT systems are fully automatic so that when the car is put in the charging place, the battery begins to be charged.

-Waterproof feature: The charging system can be inserted below the ground level and significant problems resulting from snow and ice are solved.

- Anti-sabotage feature: Because the devices are planted in the ground, they are not visible and there is no copper wire to be stolen.

- Reduced risks of electric shock: there is no need for the user to connect or disconnect power.

Power transmission through induction works in a range of misalignment. For example, tire pressure, car weight, variable car's height due to snow, and transverse tolerance when parking the

\footnotetext{
${ }^{1}$ Society of Automative Engineers
}

car will not be obstacles to charging. The possibility of using such system for dynamic charging of moving vehicles through the roadbed is another advantage of IPT system.

Combining two systems of IPT and solar panel is a new idea and few studies have been carried out in this regard. For example, mobile charging with wireless transmission system and solar panel has been simulated for low-power conditions [3]. It has been investigated for home use with focus on how to design the magnetic core [4], and for developing an economic system with low efficiency [5]. In other cases, dc/dc converters have been used to connect the panel to a common DC bus, but the MPPT and control method have not been studied [6],[7]. Many studies have investigated the transmission of power through induction. After advances in manufacturing semiconductors, the frequency used in these systems has increased, which can increase the efficiency and reduce costs. All of these systems have been faced with the issues bifurcation. Also, ferrite has not been used to form the field. Therefore, in practice, when these systems are place next to the ferrimagnetic chassis of the vehicle, they go out of regulation and do not work well. Recently, several IPT power transfer systems have been presented, but no information has been presented on their efficiency [8]. Good studies have been carried out on how to design power transmission pads [9-12], but none of them provides a comprehensive process of design. Research has been done on dynamic charging of moving cars, which is considered a significant progress, but their efficiency is limited to $85 \%$ and their transmitted power to $60 \mathrm{~kW}$ [13-16]. However, in such cases, it is possible that the costs of necessary parts lead to obstacles. Other studies have been carried out in the field of dynamic charging of moving vehicles [17], [18], which are still in the early stages of research and are only focused on the design of the magnetic core. In this study, an IPT system is introduced that are designed to transfer 5 kilowatts and has an efficiency of above $90 \%$. The system is investigated in two modes. 
-When the IPT system is connected to a separate solar panels and MPPT unit.

-When the IPT system is only connected to the solar panel.

The latter mode, is the proposed system in this study, where PV is combined with IPT so that without the need for a separate MPPT unit, the panel works at Maximum power point (MPP). The main advantage of the proposed system is that by eliminating the DC/DC converter responsible for MPPT, and by adopting a new strategy in the design and control of IPT system, the maximum power can be achieved from the solar panel. Lack of need for DC/DC converter and its removal increase the efficiency. Figure 1 is the schematic presentation of the system.
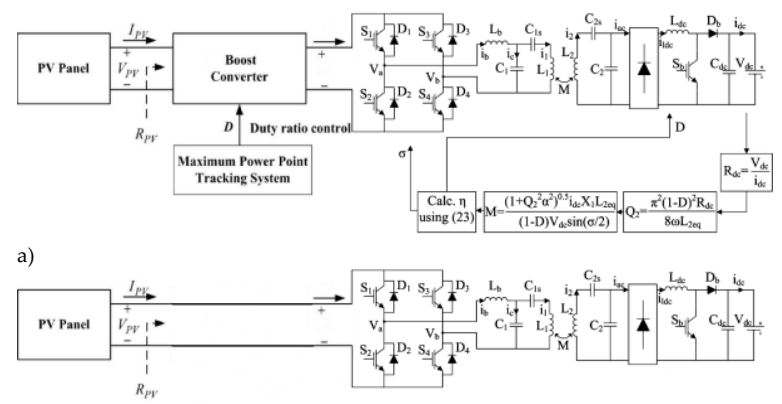

b)

Figure 1:The complete schematic presentation of the system.a) conventional, b)suggested

The remainder of this article will be presented in four parts: In the second part, the theory of circuits used will be discussed. In the third part, characteristic of components used are described. In the fourth part, the simulation process and the results are explained followed by a conclusion.

\section{The theory of the system}

Power transmission through electromagnetic induction refers to a system where electrical power transfers from a primary fixed (not moving) source through a large air gap to a secondary circuit, which can be fixed or moving. This power transmission occurs between two windings, the structure of which is similar to that of a transformer, with the difference that due to the large air gap, primary and secondary leakage inductance is high and the couple inductance is weak. This leads to high magnetizing current and because of the air core, no core losses occur. In order to increase efficiency and energy transmission, compensation capacitor is used in the secondary to improve the power transmission capability and in the primary to reduce the nominal VA, so that power is transmitted at a power factor of one [19]. Capacitors can be used in primary and secondary sides for creating resonance in the IPT circuit. They can be used in series or parallel. The reason for use of series topology in this study is that capacitance choice for primary and secondary capacitors is independent of the mutual inductance or load variations and only depends on the primary and secondary selfinductance and their compensation capacitor. Therefore, the system is suitable for applications with variable winding orientation or load. In fact, by changing these parameters there is no need to change the frequency [20]. Some assumptions should be considered in the design according to the famous formula of IPT power transmission as follows [21].

$$
P_{\max }=\omega I_{1}^{2} \frac{M^{2}}{L_{2}} Q_{2}=S U \cdot Q_{2}
$$

Where, $\mathrm{P}_{\max }$ is the maximum power transfer, $\omega$ is the frequency, $I_{1}$ is the current in the primary winding, $\mathrm{M}$ is the mutual inductance between the primary and secondary pads, $\mathrm{L}_{2}$ is self-inductance of the secondary pad, $\mathrm{Q}_{2}$ is the quality factor of the secondary resonant circuit, and $\mathrm{SU}$ is the uncompensated power.

After taking into account the amount of transmitted power, one of the assumptions to be considered is the frequency. A frequency should be selected that creates a balance between cost, power supply complexity, and the ability to transfer power from the electromagnetic structure. The power transmission capability is the most important function to be considered while determining the frequency. In theory, this relationship is linear, but the increase in core losses and boost effect causes it to deviate from the linear state. On the other hand, with increasing frequency, the construction cost and complexity of power supply structure will increase [22]. After determining the power transmission, $\mathrm{I}_{1}$, Frequency and $\mathrm{Q}_{2}$ are selected based on the process mentioned in [22] and $\frac{M^{2}}{L_{2}}$ 
is defined based on the height and size of the pads.

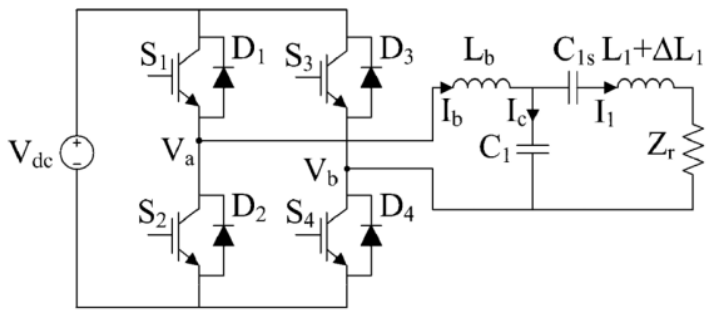

Figure 2: LCL resonant converter circuit

The reasons for using LCL converters, as seen in Figure 2, are as follows:

- The inverter only provides for real-time losses and resonant tank losses and the current in the first branch is limited with spinning in the resonance tank. For example, when $\mathrm{Q}_{1}>1$ (quality factor of LCL resonant converter in primary), and $\mathrm{Ib}_{\mathrm{b}}<\mathrm{I}_{1}$ (Figure 2) the switches have little conduction losses and the converter works with maximum efficiency.

-The output current is load-independent and this steady current is ideal for application of IPT. The initial current depends only on one control parameter, so that uncompensated power (SU) and output power can be directly controlled.

For designing LCL converter, reactance of each branch is tuned using the following equation.

$X_{1}=\omega L_{1 e q}=\omega L_{b}=\frac{1}{\omega C_{1}}=\omega L_{1}-\frac{1}{\omega C_{1 s}}$

where $X_{1}$ is the LCL converter reactance with series tuning, Lleq is Equivalent primary pad inductance with series tuning, $\mathrm{Lb}$ is the bridge inductance of LCL converter, $\mathrm{C}_{1}$ is parallel tuning capacitor on the primary, $\mathrm{L}_{1}$ is selfinductance of primary pad, and $C_{1 s}$ is series tuning capacitor on the primary.

In this system, phase shift control or symmetric voltage cancellation (SVC) [23] is used to control the I1 current. This is done with the control parameter $\sigma$. Primary current with regard to this control parameter is determined from the following equation.

$I_{1}=\frac{2 \sqrt{2} V_{d c}}{\pi X_{1}} \sin \left(\frac{\sigma}{2}\right)$ where, $V_{\mathrm{dc}}$ is $\mathrm{DC}$ input voltage to the primary LCL converter, and $\sigma$ is the conduction angle control variable of SVC.

Thus, the maximum track current that can be obtained from the primary occurs when $\sigma$ is equal to 180 degrees. $\mathrm{Zr}$, which is the reflected impedance on the primary from secondary side in resonant conditions is calculated in accordance with the following formula.

$Z_{r}=\frac{\omega^{2} M^{2}}{Z_{2}}=\omega \frac{M^{2}}{L_{2 e q}}\left(Q_{2 v}-1 . j\right)$

where, $\mathrm{Z}_{2}$ is secondary impedance, $\mathrm{Q}_{2 \mathrm{v}}$ is voltage quality factor of the secondary resonant circuit, and L2eq is equivalent secondary pad inductance with series tuning.

If coupling changes, the values of $\mathrm{Zr}$ and $\Delta L_{1}$ change substantially and increase the bridge current from $\mathrm{Ib}$ compared to its nominal value. The general form of $\mathrm{Ib}$ current in the LCL circuit can be written as follows [24].

$I_{b}=\frac{\left(V_{a b}\right)}{X_{1}^{2}}\left(j \omega \Delta L_{1}+Z_{r}\right)$

where, $\mathrm{V}_{\mathrm{ab}}$ is $\mathrm{AC}$ output voltage of $\mathrm{H}$-bridge and $\mathrm{Ib}$ is AC bridge inductor current of LCL converter. Secondary circuit with self-control is shown in Figure 3. Reasons for choosing parallel resonant circuit are as follows:

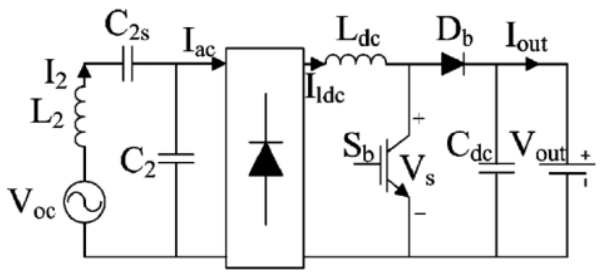

Figure 3:The secondary circuit of IPT system

-This parallel resonant circuit acts as a current source in steady state conditions [25] and is ideal for charging any type of batteries.

- Sb switch can be used to regulate the output voltage [21]. Using the duty cycle of the switch, the output voltage can be maintained constant. The tuning of this parameter proportionate to changing load is done according to formula (6). Also it can act as a battery protection circuit, when the primary and secondary connection fails. 
$D=\left(1-\frac{Q_{2 V}}{Q_{2 V m}}\right)$

Where, $\mathrm{D}$ is the control duty cycle of secondary boost converter, and $\mathrm{Q}_{2 \mathrm{vm}}$ is the maximum voltage quality factor at maximum load condition.

Operating this switch at high frequency results in reflection of $\mathrm{Zr}$ impedance to the primary circuit and has the lowest electromagnetic interference compared to lowfrequency switching. The open circuit voltage is determined by the following formula.

$V_{o c}=j \omega M I_{1}$

where, $V_{o c}$ is the voltage measured when secondary IPT pad is open circuited. If we model the battery as a DC equivalent resistance, the output power of the system can be calculated with the following well-known formula.

$$
P_{\text {out }}=P_{\max }(1-D)=\omega I_{1}^{2} \frac{M^{2}}{L_{2 e q}} Q_{2 v}(1-D)
$$

Where, Pout is the output power transferred in IPT system and $\mathrm{Q}_{2 \mathrm{v}}$ is obtained as follows.

$$
Q_{2 v}=\frac{R_{a c}}{X_{2}}=\frac{\pi^{2}(1-D)^{2} R_{d c}}{8 \omega L_{2 e q}}
$$

where, $\mathrm{R}_{\mathrm{dc}}$ is DC equivalent resistance of the battery under steady state and $X_{2}$ is the reactance of the secondary resonant tank.

$\mathrm{Q}_{2 \mathrm{v}}$ is different from $\mathrm{Q}_{2}$ (which is used in (1)). $\mathrm{Q}_{2}$ is the overall quality factor of the secondary resonant circuit and is the result of multiplying the voltage $\mathrm{Q}_{2 \mathrm{v}}$ by current $\mathrm{Q}_{2 \mathrm{i}}$ [26]. In formula (10), Lzeq should be chosen in such a way that the maximum power requirements in (8) is met. Ldc keep the rectifier current continuous and its selection is defined in [27]. The most important issue in the IPT system is controlling the power (or the current) used to charge. To this end, relations (3) and (8) are combined to obtain equation (11).

$$
X_{2}=\omega L_{2 e q}=\left(\omega L_{2}-\frac{1}{\omega C_{2 s}}\right)=\frac{1}{\omega C_{2}}
$$

where, $C_{2 s}$ is series tuning capacitor on the secondary and $C_{2}$ is parallel tuning capacitor on the secondary.

$$
P_{o u t}=\frac{V_{d c}{ }^{2}}{\omega^{2}} \frac{M^{2}}{L_{1 e q}{ }^{2} L_{2 e q}{ }^{2}} R_{d c}(1-D)^{3} \sin ^{2}\left(\frac{\sigma}{2}\right)
$$

As can be seen, he transmitted power to the battery depends on two parameters $\mathrm{D}$ and $\sigma$ as a secondary arbitrary parameter [24] and $\sigma$ as the primary current control parameter [28]. Several methods have been proposed for obtaining an algorithm for IPT convertor. In one method, primary track current control is used by itself [29], [30]. In another, the primary track current is controlled via $\sigma$ while $\mathrm{M}$ varies. $\mathrm{D}$ parameter is used to neutralize load resistance changes. Another method can be used which acts more efficiently relative to load changes and coupling. In this case, the IPT system is divided into several parts and the efficiency of each part is analyzed. Given that conduction losses constitute a large part of the losses of the entire converter. In this article, only conduction losses are considered, because the inverter bridge switching losses can vary significantly, and operation of any semiconductor switch strongly depends on the temperature and internal parameters.

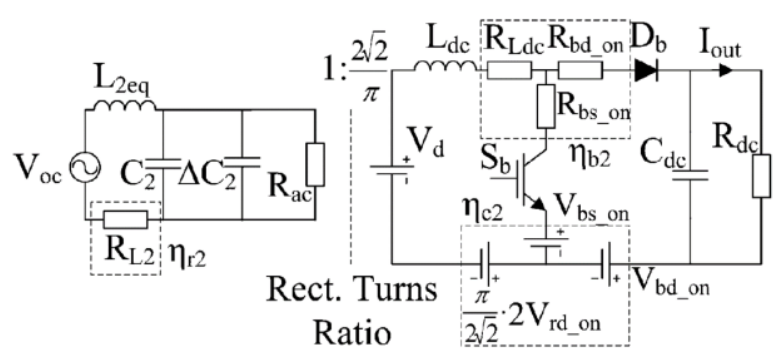

Figure 4:Equivalent secondary circuit of IPT for calculating efficiency

Figure 4 is considered as the secondary IPT circuit. Efficiency is investigated in two parts of resonant tank $\left(\eta_{r 2}\right)$ and boost converter $\left(\eta_{b 2}, \eta_{2 c}\right)$. In boost converter, conduction losses is separated into two parts: the forward voltage drop at zero current ( $\mathrm{V}_{\text {bd-on, }} \mathrm{V}_{\text {bs-on, }}$ and $\mathrm{V}_{\text {rd-on }}$ ) and the equivalent linear resistance in series. Rldc is the sum of the equivalent series resistance (ESR) in $L_{d c}$ and linear resistance of diodes in bridge 
rectifier. For more simplicity, the inductor current ripple is assumed to be zero. Therefore, regardless of the voltage drop after rectification, the efficiency of the boost converter is as follows.

$\eta_{b 2}=\frac{P_{\text {out }}}{P_{\text {out }}+P_{\text {Losses }}}=\frac{P_{\text {out }}}{P_{\text {out }}+P_{\text {Ldc }}+P_{\text {swich }}+P_{\text {diode }}}$

Since only linear resistance is considered, the above formula can be rewritten as follows.

$$
\eta_{b 2}=\frac{1}{1+\frac{R_{L d c}+D R_{b s-o n}+(1-D) R_{b d-o n}}{(1-D)^{2} R_{d c}}}
$$

where, RLdc is ESR of DC inductor and two times linear on resistance of rectifier, Rbd-on is Linear on resistance portion of boost converter diode, Rbs-on is Linear on resistance portion of IGBT and $\eta_{b 2}$ is Efficiency of secondary boost converter without voltage drop.

Assuming that Rbs-on is almost equal to Rbd-on, the relationship can be simplified as follows.

$$
\eta_{b 2}=\frac{1}{1+\frac{8 \omega C_{2}\left(R_{L d c}+R_{b d_{-} o n}\right)}{\pi^{2} Q_{2 v}}}
$$

The losses due to forward voltage drop, regardless of the resistance, and with the assumption that $V_{b d-o n}$ and $V_{b s-o n}$ are equal can be expressed as follows.

$$
\eta_{c 2}=\frac{1}{1+\frac{\pi V_{r d_{\_} o n}+\sqrt{2} V_{b d_{\_} o n}}{\sqrt{2}(1-D) V_{\text {out }}}}
$$

where, $\eta_{c 2}$ is the efficiency of secondary boost converter with linear resistance loss, $V_{\text {rd-on }}$ is the voltage drop portion of secondary rectifier diodes, $V_{\text {out }}$ is the DC output voltage of secondary decoupling circuit, and $\mathrm{Vbd}_{\mathrm{b}-o n}$ is the voltage drop portion of boost converter diode.

In the next step, for secondary resonant circuit, the detuning effect of resonant circuit resulting from inductance changes is considered. Here, the pad inductance is considered constant and the parallel capacitor is considered variable. The losses are proportional to the magnitude of $\mathrm{I}_{2}$.
$\left|I_{2}\right|=I_{a c} \sqrt{1+Q_{2 v}{ }^{2}(1+\alpha)^{2}}$

where, $\alpha$ is normalized capacitance ratio, Iac is the AC current through secondary rectifier, and $\mathrm{I}_{2}$ is the secondary pad current.

$\alpha=\left|\frac{\Delta C_{2}}{C_{2}}\right|$

where, $\Delta C_{2}$ is equivalent change in secondary tuning capacitance due to variations in $\mathrm{L} 2$. Finally, the efficiency of the secondary resonant tank alone is derived by:

$\eta_{r 2}=\frac{1}{1+\frac{\omega C_{2} R_{L 2}}{Q_{2 v}}\left(1+Q_{2 v}{ }^{2}(1+\alpha)^{2}\right)}$

where, $R_{\mathrm{L} 2}$ is the ESR of secondary pad. Now, the relations (13), (15) and (18) are multiplied to obtain the efficiency of the secondary part. Below, calculating the efficiency of LCL converter and its resonant circuit is discussed. According to the equivalent circuit of Figure 5:

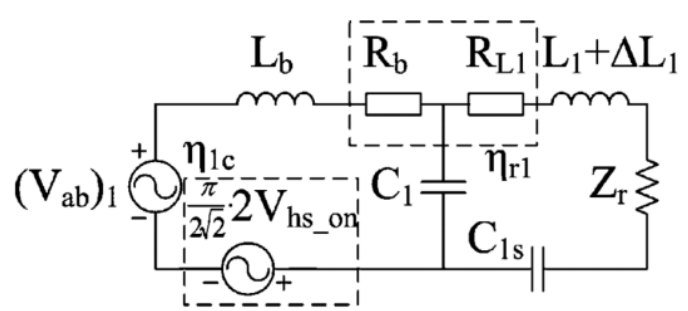

Figure 5:Primary IPT circuit (LCL resonant converter) for assessing efficiency

First $\mathrm{Zr}$ should be calculated. For this purpose, first the parallel impedance of the secondary circuit is obtained as follows.

$Z_{p}=R_{a c} \square \frac{1}{j \omega \Delta C_{2}}=\frac{R_{a c}\left(1-j Q_{2 v} \alpha\right)}{1+Q_{2 v}{ }^{2} \alpha^{2}}$

where, $Z_{p}$ is the impedance of the secondary circuit without tuning. It should be noted that all the ESR losses of the secondary are not taken into account, because their values are negligible compared to reactance and load resistance. $\mathrm{I}_{2}$ current is obtained by: 
$I_{2}=\frac{V_{o c}-V_{a c 2}}{j \omega L_{2}}=\frac{j \omega M I_{1}-\frac{M}{L_{2 e q}} I_{1} \frac{R_{a c}\left(1-j Q_{2 v} \alpha\right)}{1+Q_{2 v}{ }^{2} \alpha^{2}}}{j \omega L_{2 e q}}$

Reflected impedance to the primary is:

$Z_{r}=\frac{\omega^{2} M^{2} I_{2}}{V_{o c}}=\frac{\omega M^{2}}{L_{2 e q}} \frac{Q_{2 v}}{1+Q_{2 v}{ }^{2} \alpha^{2}}+j \frac{\omega M^{2}}{L_{2 e q}}\left(-1-\frac{Q_{2 v}{ }^{2} \alpha}{1+Q_{2 v}{ }^{2} \alpha^{2}}\right)$

It should be noted that if $\Delta C_{2}$ is set at zero, (21) can be simplified to (4). As before, linear resistance losses are separated from the forward voltage drop at zero current. Similar to (11), the efficiency for the primary considering only linear resistance is:

$$
\eta_{r 1}=\frac{1}{1+\frac{R_{l 1}+R_{b} \omega^{2} C_{1}^{2}\left(\left(R_{l 1}+\operatorname{Re}\left(Z_{r}\right)\right)^{2}+\left(\omega \Delta L_{1}+\operatorname{Im}\left(Z_{r}\right)\right)^{2}\right)}{\operatorname{Re}\left(Z_{r}\right)}}
$$

where, $R_{b}$ is the ESR of AC bridge inductor and two times linear on resistance of IGBT, RL1 is the ESR of primary IPT pad, $\Delta \mathrm{L}_{1}$ is the change in primary IPT pad inductance due to height variations, and $\eta_{r l}$ is the efficiency of primary LCL converter without voltage drop. As in (14), the efficiency due to forward voltage drop is achieved by.

$$
\eta_{c 1}=1-\frac{\pi V_{h s_{-} \text {on }}}{\omega L_{b} \sqrt{\frac{2 P_{\text {out }}}{\operatorname{Re}\left(Z_{r}\right)}}}
$$

where, $V_{h s_{-} \text {on }}$ is the voltage drop portion of IGBT and $\eta_{c 1}$ is the efficiency of primary LCL converter without linear resistance loss. Finally by multiplying efficiency relationships for different parts, the overall efficiency of the IPT is obtained by:

$\eta=\eta_{b 2} \cdot \eta_{c 2} \cdot \eta_{r 2} \cdot \eta_{r 1} \cdot \eta_{c 1}$

With these calculations, the maximum efficiency can be obtained analytically. All the required values are from the secondary side of IPT. Only the control signal $\sigma$ is sent toward the primary side and can be used in control of IPT separately. The equivalent circuit of a solar panel is shown in Figure 6.

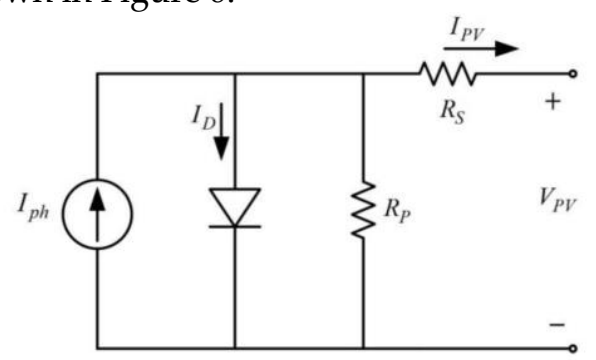

Figure 6: Equivalent solar panel circuit with a diode

In the equivalent solar panel the current source $\mathrm{I}_{\mathrm{ph}}$ is connected with a parallel diode, parallel resistance $R_{p}$ and series resistance $R_{s}$. The current and voltage of solar panel $\mathrm{I}_{\mathrm{pv}}$ and $\mathrm{V}_{\mathrm{pv}}$ are shown in the following relationships.

$$
\begin{aligned}
& I_{p v}=I_{p h}-I_{D}-\frac{V_{p v}+R_{s} I_{P V}}{R_{p}} \\
& I_{D}=I_{0}\left[\exp \left(\frac{q\left(V_{P V}+R_{s} I_{P V}\right.}{n A K T}\right)-1\right]
\end{aligned}
$$

$\mathrm{I}_{\mathrm{ph}}$ is produced proportional to the light. ID is the diode current, $\mathrm{I}_{0}$ is the reverse saturation current, $\mathrm{Q}$ is the electron charge that is constant, $\mathrm{K}$ is Boltzmann constant, $\mathrm{T}$ is panel surface temperature in Kelvin, A is ideal diode constant, and $n$ is the number of series diodes. $\mathrm{I}_{\mathrm{ph}}$ current is dependent on temperature and sunlight [31]. To put the solar panel at maximum power, MPPT unit is used. This converter is of DC/DC boost type and the most common algorithm that is used in it is Perturb and Observer. By measuring the output power of the panel, the load voltage changes by DC/DC converter so that the operating point of the panel gets close to MPP [32].

\section{Profile of components used in the system}

The purpose is to charge the battery in the secondary side of the IPT converter. The battery is 300 volts Lifepo4, because this voltage level is more appropriate to operate the electric motor driving the vehicle and only a few transistors are needed to change it into ac signal suitable for feeding the engine. According to the battery profile, the output voltage of the boost converter can be determined. This voltage is 250 to 365 
volts, depending on the battery charge type. This IPT converter has been designed for transmission up to the power of $5 \mathrm{~kW}$. According to (1) and assuming that $I_{1}$ current is limited to $40 \mathrm{Amps}$, the operating frequency is $20 \mathrm{kHz}$ and the value of $Q_{2}$, which is proportional to the load, is 5. All values and features were selected based on available and popular technology and equipment. The design procedure is explained in [33]. For designing pads, from among the pads proposed at [9], [11], [12], [14], and [10], a pad with high coupling factor and proper dimensions was chosen. The pad has a diameter of $183 \mathrm{~mm}$ and is circular as shown in Figure 7.

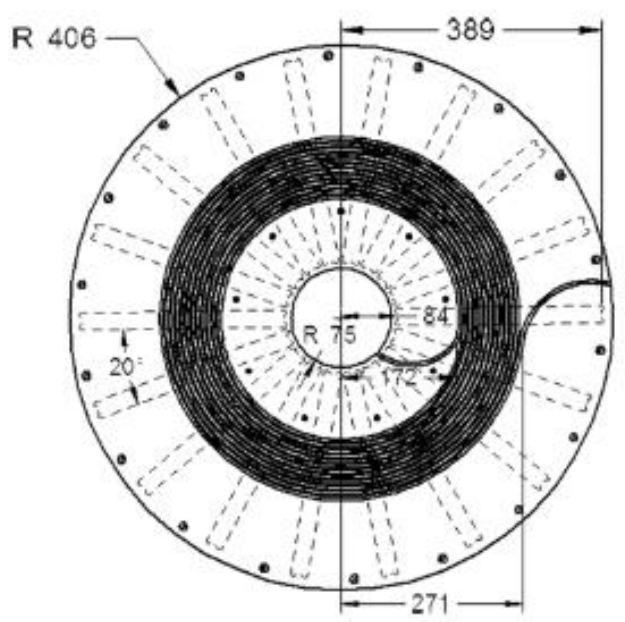

Figure 7: The selected pad

Other physical properties of the pad are explained in [10]. The transmitter and receiver pads are identical. The windings used in the pads are 1300 Litz wire AW636. The pads with these specifications are capable of delivering up to $10 \mathrm{~kW}$. As previously mentioned, $\frac{M^{2}}{L_{2}}$ depends on the height and size of the pads, as shown in Figure 8.

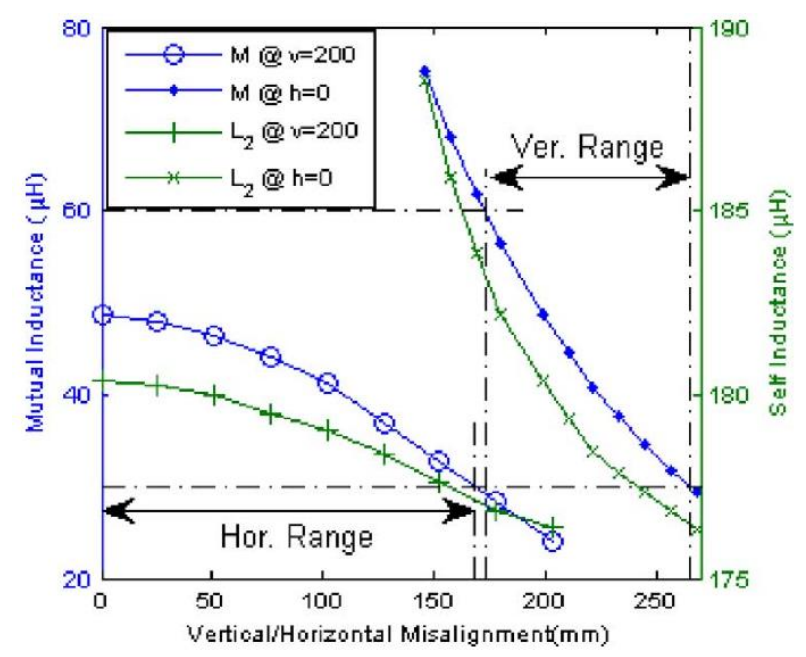

Figure 8: Mutual- and self- inductance relative to transverse and elevation displacement

To deliver 5 kilowatts, according to equation (1), mutual inductance must be $\mathrm{M}>30 \mu \mathrm{H}$ or the coupling coefficient must be $\mathrm{K}>0.17$. To limit the stress imposed on electronic parts, the maximum is considered as double. In this system, coupling can change up to $100 \%$. $K_{\max }=200 \% \mathrm{~K}_{\min }$, in which case, in accordance with (4), the reflected impedance to the primary will be 4 times. With these changes, $I_{1}$ and the fundamental component of $\mathrm{AC}$ output voltage $\left(\mathrm{V}_{\mathrm{ab}}\right)_{1}$ are controlled to be inversely proportional to the coupling change with a variation of 2 times [25]. The maximum $\mathrm{Ib}$ should be at least two times the minimum. The bridge current inductor should handle 42A, which is 2.5 times the minimum current. Design parameters for this IPT system are shown in tables one and two.

Table 1: Design parameters for LCL convertor

\begin{tabular}{|c|c|c|c|}
\hline Parameter & Value & Parameter & Value \\
\hline $\mathrm{V}_{\mathrm{dc}}$ & $400 \mathrm{~V}$ & $\mathrm{C}_{1 \mathrm{~s}}$ & $663 \mathrm{nF}$ \\
\hline $\mathrm{X}_{1}$ & $9.21 \Omega$ & $\mathrm{L}_{1}($ Figure 3$)$ & $177-188 \mathrm{uH}$ \\
\hline $\mathrm{I}_{1 \max }$ & $39 \mathrm{~A}$ & $\mathrm{~L}_{1 \text { short }}$ & $161-172 \mathrm{uH}$ \\
\hline $\mathrm{L}_{\mathrm{b}}$ & $73.3 \mathrm{uH}$ & $\omega$ & $1.257 \times 10^{5} \mathrm{rad} / \mathrm{s}$ \\
\hline $\mathrm{C}_{1}$ & $885 \mathrm{nF}$ & & \\
\hline
\end{tabular}

Table 2: Design parameters for secondary IPT

\begin{tabular}{|c|c|c|c|}
\hline Parameter & Value & Parameter & Value \\
\hline $\mathrm{V}_{\text {out }}$ & $300 \mathrm{~V}$ & $\mathrm{~L}_{\text {dc }}$ & $550 \mathrm{uH}$ \\
\hline $\mathrm{X}_{2}$ & $10.6 \Omega$ & $\mathrm{I}_{\text {out }}$ & $0-17 \mathrm{~A}$ \\
\hline $\mathrm{C}_{2}$ & $745 \mathrm{nF}$ & $\mathrm{C}_{2 \mathrm{~s}}$ & $666 \mathrm{nF}$ \\
\hline $\mathrm{L}_{2}$ & $177-188 \mathrm{uH}$ & & \\
\hline
\end{tabular}

$$
L_{d c} \text { is DC inductance of secondary }
$$
decoupling circuit, $I_{1-M A X}$ is the maximum primary track current in LCL converter and $I_{\text {out }}$ 
is the DC output current of secondary decoupling circuit. The information required to be exchanged between primary and secondary circuits, like signals needed by control circuit in the primary and the feedback the secondary circuit receives, or to determine the placement of two pads to each other, which helps the driver to park properly, can be transmitted by RFID or Optic radio signals.

For designing a proper solar panel and MPPT, the load changes should be evaluated and predicted. In other words, the resistance that MPPT faces should be in a range that the panel can be put in optimal position. According to the characteristics of the selected panel which is summarized in Table 3, the minimum resistance the MPPT unit should face to operate properly is $58 \mathrm{ohm}$.

Table 3: Characteristics of the selected panel

\begin{tabular}{|l|l|l|l|l|l|l|}
\hline $\mathrm{V}_{\mathrm{oc}}$ & $\mathrm{I}_{\mathrm{sc}}$ & $\mathrm{I}_{\mathrm{pv}, \mathrm{n}}$ & $\mathrm{K}_{\mathrm{v}}$ & $\mathrm{K}_{\mathrm{i}}$ & $\mathrm{N}_{\mathrm{s}}$ & $\mathrm{N}_{\mathrm{p}}$ \\
\hline 42.1 & 3.56 & 3.87 & -0.08 & 0.065 & 12 & 2 \\
\hline
\end{tabular}

\section{Simulation and Results}

Here two systems, one with MPPT and one without MPPT are compared. The purpose is to achieve higher efficiency. In the first topology, MPPT and IPT controllers act independently. In the IPT, the parameter D of the boost converter, as primary control variable (inner loop) and conduction angle of the inverter $(\sigma)$ are continuously updated, so that the output power (or current) is regulated. Equivalent load resistance is measured by sampling voltage and current. Two voltage and current sensors is required for battery protection. Coupling coefficient is determined using mathematical calculations. To this end, first, the primary side current is obtained. If the primary voltage is constant, (3) can be used for its measurement. But in this case, CT (current transformer) is used to measure it. Given the I current estimates and $\mathrm{V}_{\mathrm{dc}}, \mathrm{V}_{\text {out, }}$ and Iout , M (and K) can be directly measured. The related equation is as follows.

$$
M=\frac{\sqrt{1+Q_{2 v}{ }^{2} \alpha^{2}}}{1-D} \frac{I_{o u t} X_{1}}{V_{d c} \sin \left(\frac{\sigma}{2}\right)} L_{2 e q}
$$

The efficiency can be calculated using the system parameters and replacing them in the efficiency formulae. In this way, there is no need for additional costs for installation of sensors in the primary and for information exchange between the two pads. In this case, only the Sigma signal is sent to the primary. With a change in Sigma, the system follows the maximum calculated efficiency to reach it. At the beginning, $\sigma$ is $100 \%$ and $\mathrm{D}$ is zero. Along operation, Sigma reduces and gets close to maximum efficiency. D helps regulate load output voltage so that maximum efficiency in IPT is achieved. One might think that the highest efficiency is achieved when the primary current is at its minimum or D is zero. However, due to conduction losses in the inverter according to formulas (22) and (23) at low sigma, maximum efficiency does not happen at minimum current.

Simulation results in the system with independent MPPT unit show that at 45 ohms output load, which is equivalent to a battery inserted, the maximum efficiency was achieved at $\mathrm{D}=0.65, \sigma=47.12$ and $\eta=91.35 \%$. $\mathrm{D}$ changes also affect Sigma. If we disable the control loop $\mathrm{D}$, the output voltage reaches 466 volts.

In the proposed system, via predicting load and designing accordingly, Mppt algorithm can be applied in the IPT converter control circuit. Obviously, in this case, by eliminating MPPT converter, efficiency increases. In this simulated case, a panel is designed according to the required load whose MPP point is achieved at Rmpp $\approx 58$. If the resistance faced by the panel is $R_{\text {in }}$, its minimum occurs when $D$ is zero and $\sigma$ is 100 percent. When the battery is charged, the transferred resistance towards PV tends to be lower. With reduced radiation, the resistance where MPPT occurs increases. However, in this case, $R_{\text {in }}$ should be much less than $R_{m p p}$, so that with reducing $\sigma$ and increasing $D$, that increases $R_{\text {in, }}$ and approximating $R_{\text {in }}$ and $R_{m p p}$, the panel can be put at the MPP. Temperature is less effective in changing MPP point than radiation. In simulation, a simple algorithm is used that can see slope of changes and increase or decrease $\sigma$ accordingly to reach the MPP. The D parameter alone acts to regulate the output voltage in the range specified. Despite the fact that $\mathrm{D}$ affects $\sigma$, because of low speed of load change, the control loop acts separately. In this simulation it occurred at $\mathrm{D} \approx 0$ and $\sigma=47.12, \mathrm{H}=$ 
93.4\%. The waveforms related to the system without MPPT are shown below.

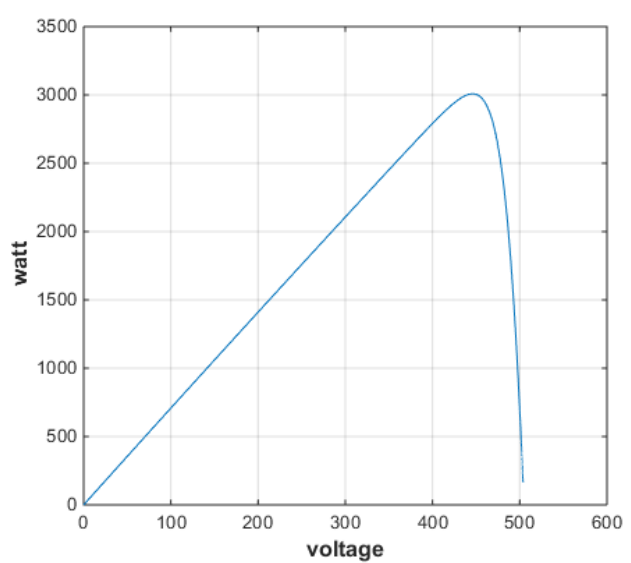

Figure 9: $P_{-} V$ feature of the selected panel

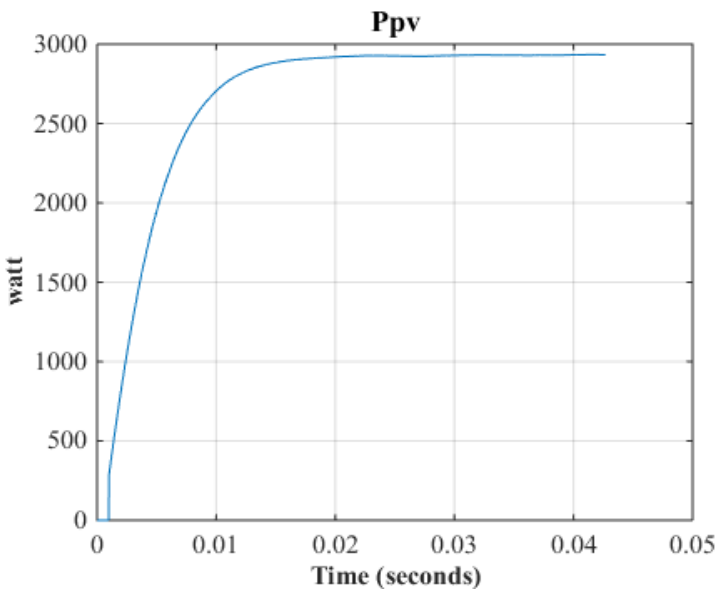

Figure 10: The panel's produced power

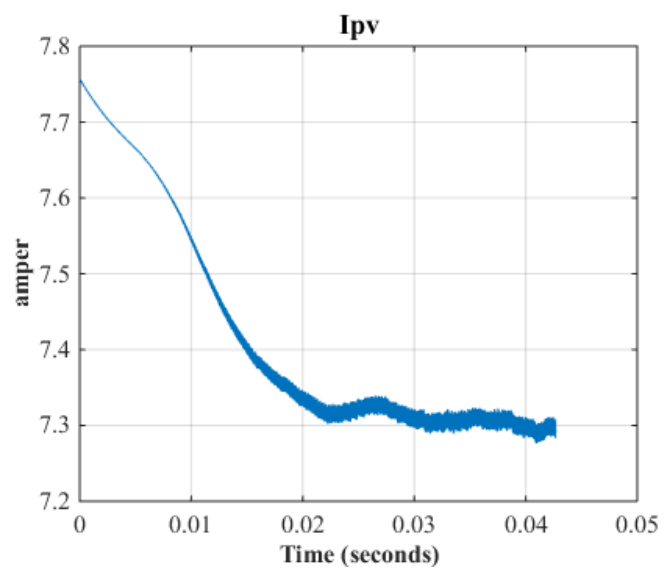

Figure 11: The output current of the solar panel

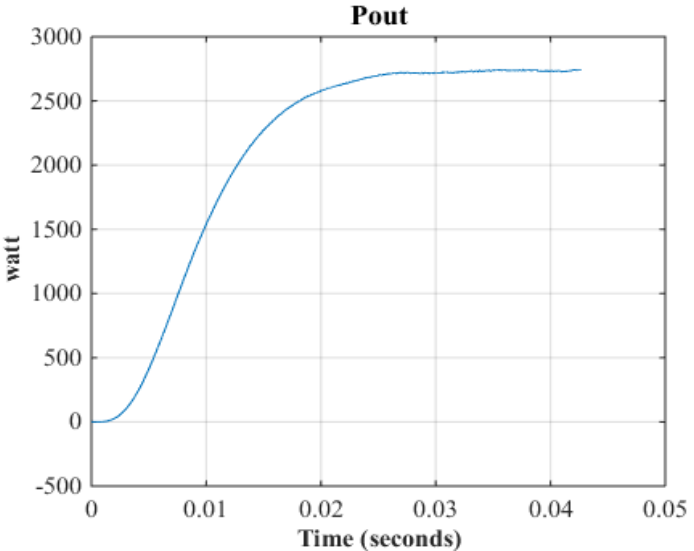

Figure 12: Load power

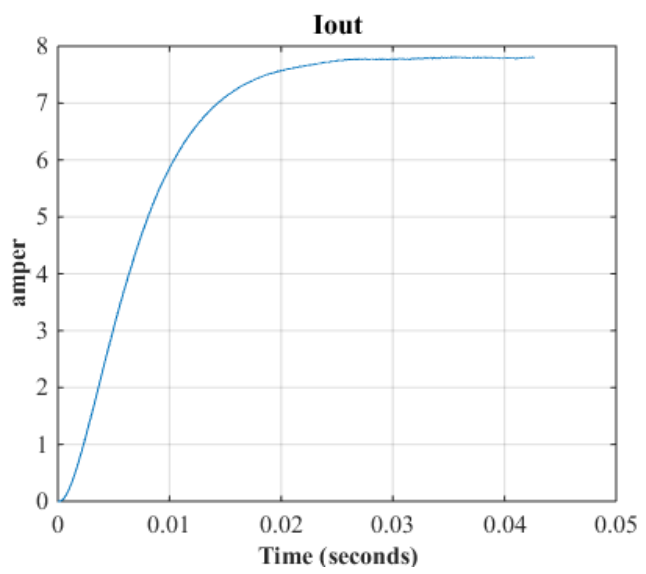

Figure 13: Load current

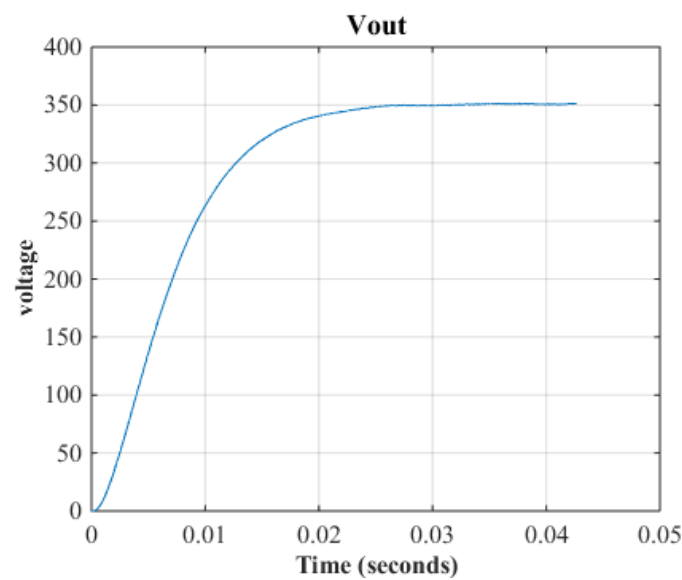

Figure 14: Load voltage

\section{Conclusion}

As the simulation results show, efficiency in the proposed system improved. But, this is not the only advantage of this system. Since the DC/DC converter responsible for MPPT was removed from the system, the system development costs reduced. One of the disadvantages of the conventional Perturb and Observer method is that it may make the system 
operation point far from the MPP. But, using the proposed system with removing the unit and implementing new control algorithms eliminated this disadvantage, so that the system worked near the MPP and higher maximum power point is obtained from the solar panel. In addition, in the new system, because of simplicity of its control circuit, the system can pass the starting fluctuations and reach stability faster. Comparing the results of the two systems shows that all of these benefits have been obtained while the proposed system is similar to the conventional system in terms of performance.

\section{References}

[1] C. C. Chan, "The state of the art of electric, hybrid, and fuel cell vehicles,"Proc. IEEE, vol. 95, no. 4, pp. 704-718, 2007.

[2] SAE, "SAE Electric Vehicle and Plug in Hybrid Electric Vehicle Conductive Charge Coupler", SAE J1772 Standard, 2001.

[3] M.Fareq, M.Fitra,M.Irwanto, Syafruddin. HS, N. Gomesh, Farrah. S, M. Rozailan ." Solar wireless power transfer using inductive coupling for mobile phone charger"

[4] S.Suja,T.Sathish Kumar,Student Member, IEEE ."Solar based wireless power transfer system s"

[5] Dimko Miskovski, Student Member, IEEE, and Sheldon S. Williamson, Member, IEEE." Modeling and simulation of a photovoltaic (PV) based inductive power transfer electric vehicle public charging station"

[6] Theodora-Elli Stamati, Pavol Bauer, Senior Member IEEE." Green energy for on-road charging of electric vehicles"

[7] Faical Turki,Abdelkader Guetif,Constantinos Sourkounis ." Contactless charging electric vehicles with renewable energy"

[8] H. Chang-Yu, J. T. Boys, G. A. Covic, and M. Budhia, "Practical considerations for designing IPT system for EV battery charging," in Proc.IEEE Veh. Power Propulsion Conf. (VPPC '09), 2009, pp. 402-407.
[9] M. Budhia, G. Covic, and J. Boys, "A new IPT magnetic coupler for electric vehicle charging systems," in Proc. 36th Annu. Conf. IEEE Ind.Electron. Soc., (IECON'10), 2010, pp. 2487-2492.

[10] M. Budhia, G. Covic, and J. Boys, "Design and optimization of circular magnetic structures for lumped inductive power transfer systems,"IEEE Trans. Power Electron., vol. PP, no. 99, pp. 1-1, 2011.

[11] M. Budhia, G. A. Covic, J. T. Boys, and C.-Y. Huang, "Developmentand evaluation of single sided flux couplers for contactless electric vehicle charging," in Proc. IEEE Energy Conversion Congr. Expo(ECCE'11), 2011, pp. 614-621.

[12] M. Chigira, Y. Nagatsuka, Y. Kaneko, S. Abe, T. Yasuda, and A.Suzuki, "Smallsize light-weight transformer with new core structure for contactless electric vehicle power transfer system," in Proc. IEEE Energy Conversion Congr. Expo (ECCE'11), 2011, pp. 260-266.

[13] S. Lee, J. Huh, C. Park, N.-S. Choi, G.-H. Cho, and C.-T. Rim, "OnLine Electric Vehicle using inductive power transfer system," in Proc.IEEE Energy Conversion Congr. Expo. (ECCE), 2010, pp. 1598-1601.

[14] H. Jin, L. Wooyoung, C. Gyu-Hyeong, L. Byunghun, and R.ChunTaek ,"Characterization of novel inductive power transfer systems for on-line electric vehicles," in Proc. 26th Annu. IEEE Appl. Power Electron.Conf. Expo. (APEC'11), 2011, pp. 1975-1979.

[15] J. Huh, S. Lee, C. Park, G.-H. Cho, and C.-T. Rim, "High performance inductive power transfer system with narrow rail width for On-Line Electric Vehicles," in Proc. IEEE Energy Conversion Congr. Expo.(ECCE), 2010, pp. 647-651.

[16] L. Sungwoo, L. Wooyoung, H. Jin, K. Hyun-Jae, P. Changbyung, C. GyuHyeong, and R. Chun-Taek, "Active EMF cancellation method for I-type pickup of On-Line Electric Vehicles," in Proc. 26th Annu. IEEE Appl. Power Electron. Conf. Expo. (APEC'11), 2011, pp. 1980-1983. 
[17] S.-H. Lee and R. D. Lorenz, "Development and validation of model for 95\% efficiency, $220 \mathrm{~W}$ wireless power transfer over a $30 \mathrm{~cm}$ air-gap," in Proc. IEEE Energy Conversion Congr. Expo. (ECCE), 2010, pp. 885-892.

[18] S.-H. Lee and R. D. Lorenz, "A design methodology for multi-kW, large airgap, $\mathrm{MHz}$ frequency, wireless power transfer systems," in Proc. IEEE Energy Conversion Congr. Expo. (ECCE'11), 2011, pp.3503-3510.

[19] Chwei-Sen Wang; Stielau, O.H.; Covic, G.A.; , "Design considerations for a contactless electric vehicle battery charger," Industrial Electronics, IEEE Transactions on, vo1.52, no.5, pp. 13081314, Oct. 2005

[20] S.Chopra, P. Bauer." Analysis and Design Considerations for a Contactless Power Transfer System". Delft University of Technology

[21] J. T. Boys, G. A. Covic, and A. W. Green, "Stability and control of inductively coupled power transfer systems," IEE Proc. - Electric Power Appl., vol. 147, no. 1, pp. 37-43, 2000.

[22] O. H. Stielau and G. A. Covic, "Design of loosely coupled inductivepower transfer systems," in Proc. Int. Conf. Power Syst. Technol. (PowerCon'00),2000, pp. 85-90.

[23] H. H. Wu, A. Gilchrist, K. Sealy, P. Israelsen, and J. Muhs, "Design of symmetric voltage cancellation control for LCL converters in inductive power transfer systems," in Proc. IEEE Int. Electric Machines Drives Conf. (IEMDC'11), 2011, pp. 866-871.

[24] 24.G. Elliott, S. Raabe, G. A. Covic, and J. T. Boys, "Multiphase pickups for large lateral tolerance contactless powertransfer systems," IEEE Trans. Ind. Electron., vol. 57, no. 5, pp. 1590-1598, May 2010.

[25] G. A. Covic, J. T. Boys, A. M. W. Tam, and J. C. H. Peng, "Self tuning pick-ups for inductive power transfer," in Proc. IEEE Power Electron.Specialists Conf. (PESC'08), 2008, pp. 3489-3494.

[26] N. A. Keeling, G. A. Covic, and J. T. Boys, "A unity-power-factor IPT pickup for high-power applications," IEEE
Trans. Ind. Electron., vol. 57, no. 2, pp. 744-751, Feb. 2010.

[27] P. Si and A. P. Hu, "Analyses of DC inductance used in ICPT power pick-ups for maximum power transfer," in Proc. IEEE/PES Transmission Distrib. Conf. Exhibition: Asia and Pacific, 2005, pp. 16.

[28] P. Si, A. P. Hu, J. W. Hsu, M. Chiang, Y. Wang, S. Malpas, and D. Budgett, "Wireless power supply for implantable biomedical device based on primary input voltage regulation," in Proc. 2nd IEEE Conf. Ind. Electron. Appl. (ICIEA'07), 2007, pp. 235-239.

[29] G. B. Joung and B. H. Cho, "An energy transmission system for an artificial heart using leakage inductance compensation of transcutaneous transformer," IEEE Trans. Power Electron., vol. 13, no. 6, pp. 1013-1022, Nov. 1998.

[30] P. Si, A. P. Hu, S. Malpas, and D. Budgett, "A frequency controlmethod for regulating wireless power to implantable devices," IEEE Trans. Biomed. Circuits Syst., vol. 2, no. 1, pp. 22-29, Mar. 2008.

[31] Jaw-Kuen Shiau, Min-Yi Lee, Yu-Chen Wei, and Bo-Chih Chen," Circuit Simulation for Solar Power Maximum Power Point Tracking with Different Buck-Boost Converter Topologies ",Department of Aerospace Engineering, Tamkang University, Tamsui, New Taipei City, 25137, Taiwan; 14 March 2014

[32] Trishan Esram, Student Member, IEEE, and Patrick L. Chapman, Senior Member, IEEE," Comparison of Photovoltaic Array Maximum Power Point Tracking Techniques". IEEE TRANSACTIONS ON ENERGY CONVERSION, VOL. 22, NO. 2, JUNE 2007

[33] O. H. Stielau and G. A. Covic, "Design of loosely coupled inductive power transfer systems," in Proc. Int. Conf. Power Syst. Technol. (PowerCon'00), 2000, pp. 85-90 